\title{
A Design of Network Office System Based on ASP
}

\section{Enhai Qiu and Jing Rao}

\author{
Jiangxi Industry Polytechnic College, Department of Electronic and Information Engineering; \\ Jiangxi Technical College of Manufacturing, Department of Computer Center
}

\section{Keywords: Network Office System; ASP Technology; Data Base; Identifying Code}

\begin{abstract}
As the widespread using of Internet and the development of Internet technology, Network office automation system has been applied in more and more companies. Network office automation system can not only improve the efficiency, it can also maximize and simplify resource sharing process at the same time. Thus, data delivery can be faster and more widespread. Consequently, employees will feel more comfortable and it also decreases some unnecessary costs. Based on the background mentioned above, this paper is an introduction of a design of Network Office System based on ASP technology. This paper introduces main problems and status quo on Network office automation system both at home and abroad. Then by the introduction of application platform, the key technology in this design is stated. At last, this paper specifically introduces the designs of different modules and implementation method of each module.
\end{abstract}

\section{Introduction}

Nowadays our society has entered a high speed information age. With the widespread use of Internet, the way of information delivering has become more various and information people exposed to are multiplied. How to transfer information quickly turns to be our main concern. For a long time, our media for information delivering in office has always been paper, but, traditional ways are apparently far more meeting our needs in nowadays information age. How to realize automatic data process and paperless office mode draw more and more people's attention and study.

Network Office now is a trend for Enterprises to improve efficiency and streamline administration structure. Paperless office mode can not only realize resource sharing, improve efficiency, it can also make employees will feel more comfortable and decreases some unnecessary costs at the same time. But, the coin has two sides. This paper introduces main problems and status quo on Network office automation system both at home and abroad. Then by the introduction of application platform, the key technology in this design is stated. At last, this paper specifically introduces the designs of different modules and implementation method of each module.

\section{The Main Frame of the System}

Network office system backstage design consists of the design of database and the realization of business logic. Except the management of correspondent front pages, following three aspects are also included:

Design database sheets according to practical requirements.

Update all kinds of data, including adding, deleting, fixing data information.

Realize database connection.

The main object of database design is all kinds of information attributes, such as name, type, length of data, and whether it is empty. Although we can add all kinds of information on presentation layer, we can also add information like user names, user passwords, notification and send-receive information etc., in database directly. Thus, the design of these two functions is mainly about information processing. That information is the main information shown on presentation layer. The integrity of all presentation layers' functions is realized by database management design. 


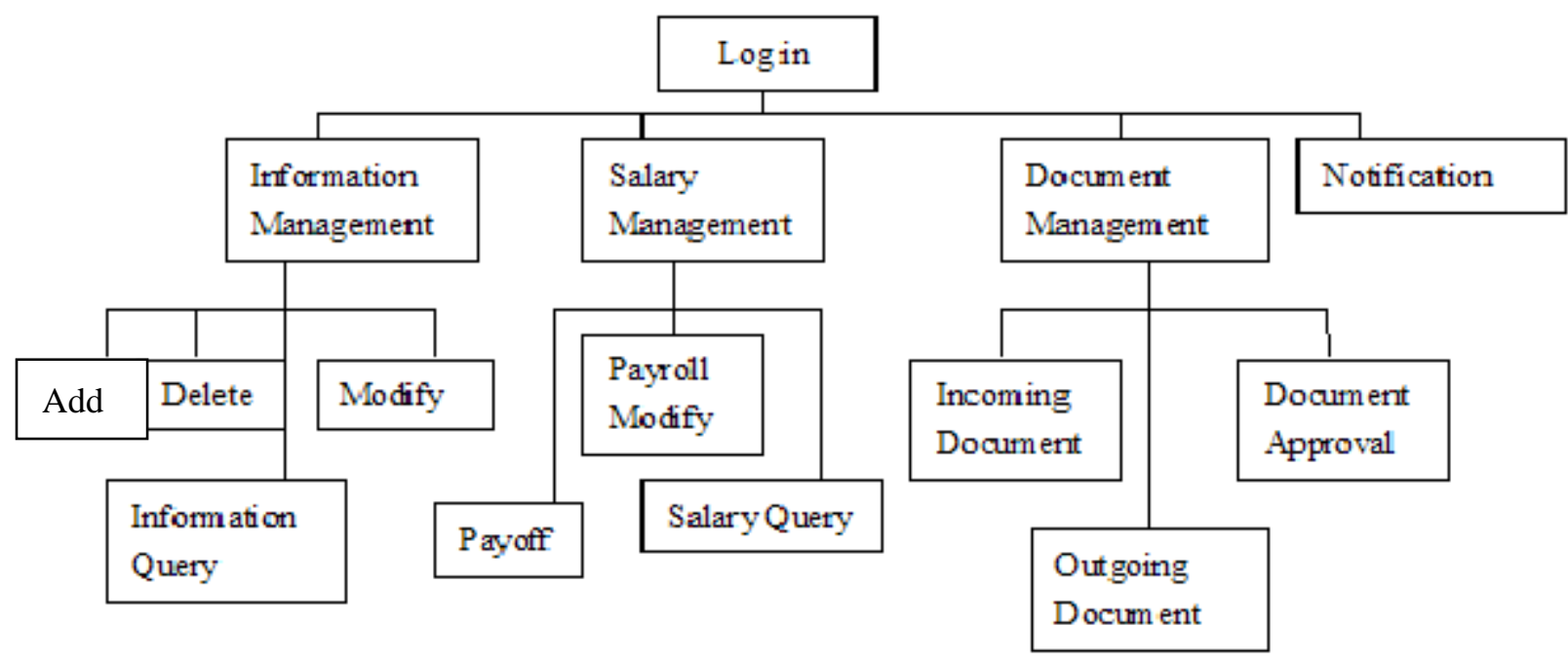

Fig 1 Function module of the system

\section{Database Design for Network Office System}

The conceptual model is the modeling of information world. Thus, a conceptual model can present conveniently and exactly those common concept in information world that we have mentioned above. In Fig. E-R, real world is described by conceptual models. It is the common basis of all kinds of data modules, thus, it's more common, more abstract and more close to real world. Data entities are: employee, document, salary and notification. Detailed description of each entity are listed in Fig.s $\mathrm{E}-\mathrm{R}$ as follows.

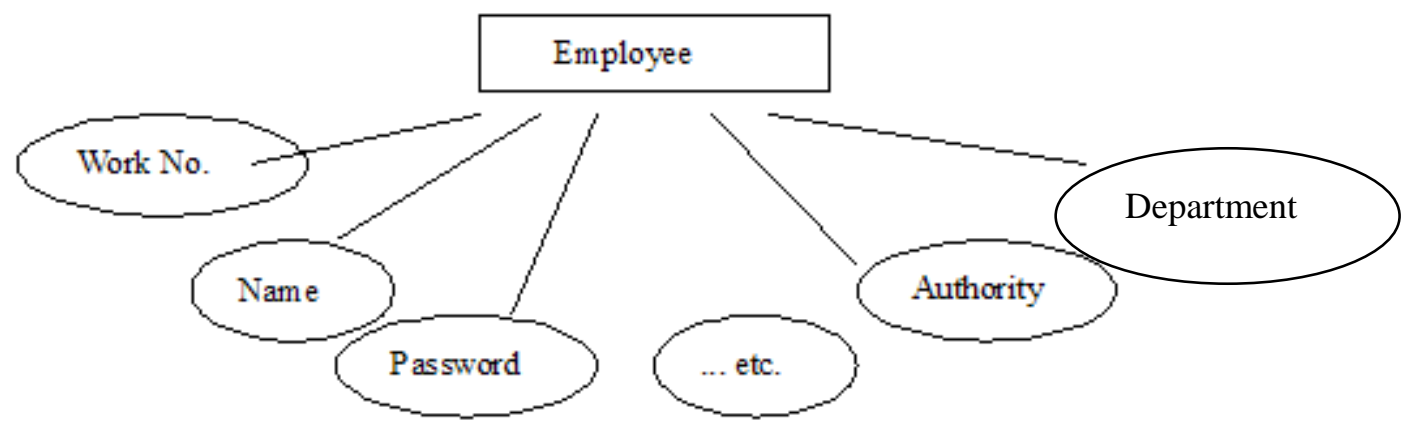

Fig. 2 Employee $\mathrm{E}-\mathrm{R}$

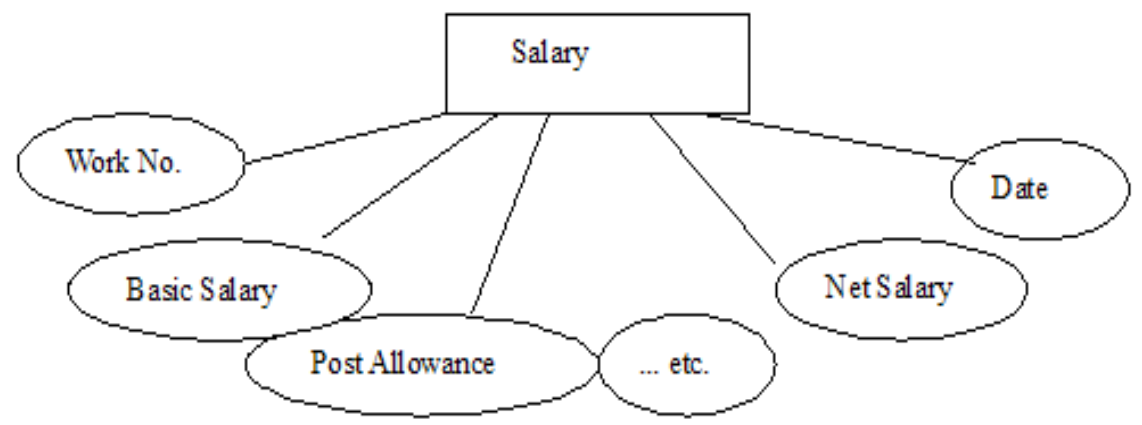

Figure 3. Salary E - R 


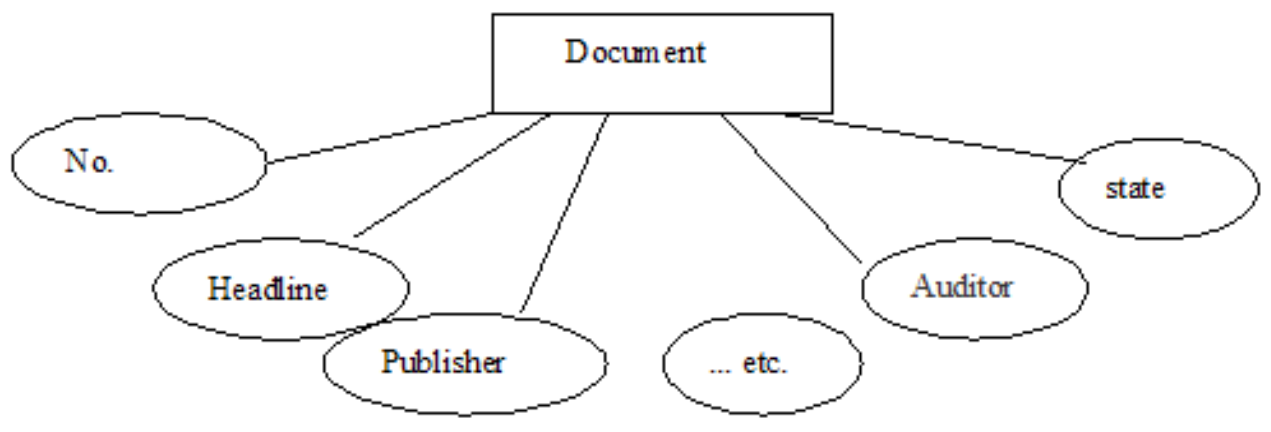

Figure 4. Document $\mathrm{E}-\mathrm{R}$

After putting into operation, workers should have regular maintenance on database to guarantee its normal performance. As database maintenance lasts for a long period and it's a professional work, thus, it requires workers master some basic database operation, such as data saving, control and storage. Database maintenance also relates to physical database and even redesign and modification of logic database. Therefore, database maintenance should be accomplished by professional technical personnel.

When log in a certain website, people are often required to enter their user names, passwords and identifying code then click to submit. After system's verification of users' legitimacy, users can then $\log$ in the website. Identifying code is a random string of characters, which generated every time when users refresh their website pages. Usually identifying code is directly shown on the pages, and users have to enter these random characters into the right place. By click "submit" button, the identifying code entered will be submitted along with the user name and the password to the Web server at the same time.

First, web server randomly generates a string of characters and saves them in internal storage. Then it uses drawing function to generate a Fig. and shows it on browser side. After users enter those characters shown on the Fig. on browser side, these characters are submitted to the server. The server will compare these characters submitted with those that saved in internal storage. If they are the same, the process will go on and if not, the browser will return to the former page and a message will appear to prompt user there is a verification code error. Programs edited by hikers are hard to recognize the identifying code, thus they cannot register and log in automatically. While users can recognize the identifying code correctly, thus it fulfills the function of prevent attack.

Of course, it's not saying that using identifying code can prevent all kinds of attack. It depends on the way of showing identifying code and the degree of disturbance. Since web server uses a certain way to send the identifying code to the browser side and shows it on pages then theoretically, tools edited by hackers can recognize it and enter it automatically. We can use different algorithms to produce identifying code to make it harder for tools edited by hackers to identify. According to the real effect, identifying code only increases the degree of difficulty for attackers. It can not fully prevent attacks.

\section{Summary}

Nowadays network office systems are emerging endlessly, but the system mentioned in this paper is based on real items, thus, it has high pertinence. Comparing with other existing network office systems, it shows some advantages in aspects of security and technology. The main contents of this paper are list as follows:

Analyzing main problems and status quo on Network office automation system both at home and abroad.

In terms of identifying code technology, first, this paper shows study result of the meaning and scope of the application of identifying code technology. Then by analyzing popular identifying code scheme, this paper offers two better schemes. They are easy to realize and have better effects, thus, the security of the system can be strengthened. 


\section{References}

[1] Liu D. Design and Realization of Community Network Office System based on ASP.NET and AJAX [J]. Journal of Henan Mechanical \& Electrical Engineering College, 2010.

[2] Jing-Fang H U. Research and Design of Paperless Office System Based on ASP [J]. Journal of Jingdezhen Comprehensive College, 2006.

[3] Xie J H, Xiao J H. The Design and Realization of Web-Based Department Office Management Information System [J]. Applied Mechanics \& Materials, 2014, 614:554-557.

[4] Li D Y. ASP Web-based System Design and Implementation of Office [J]. Information Security \& Technology, 2011.

[5] Zhang W. The Design and Realization of Network Teaching System Based on UML and ASP.NET [J]. Office Informatization, 2009.

[6] Soltis W B, Mckelvie S P. Web-based design system: US, US 20060174199 A1 [P]. 2006.

[7] Robson Sr. J F, Epperson J J, Acker Iii J F, et al. System and method that provide office management functionalities: US, US20060271399[P]. 2006.

[8] Pendlebury I M. Network enabled application software system and method: EP, US7032113 [P]. 2006.

[9] Burbridge D, Garofalo B, Steffen J, et al. Methods and apparatus for system and device design: US, US6868370[P]. 2005.

[10]Gu L W, Wang D C, Xu L Y, et al. The Design of OA System Based on B/S Structure of Colleges and Universities [J]. Procedia Environmental Sciences, 2012, 12(Part B):1280-1286.

[11]Yan-Ru Q I. Development and Implementation of Network Office Automation System [J]. Coal Technology, 2010.

[12]WANG Ziming, ZHAO Hangwen, JIAO Hong, et al. Design and Implementation of Forestry Network Office System Based on Web [J]. Central South Forest Inventory and Planning, 2012. 